\title{
PBL Teaching Model in College English Learning
}

\author{
ZhengWei
}

Zhengzhou university of industrial technology. Henan.China

Keywords: Problem-Based Learning (PBL); College English Learning

\begin{abstract}
Problem-Based Learning (PBL), a teaching mode based on solving problems, consists of three meanings: problem-based learning, project-based learning and problem-oriented and project-based learning. In this paper, the author applies the PBL in the teaching of training in the course "College English Public Basic",defining it as the first kind:problem-based learning. This problem-oriented model takes problem-solving as its driving force,group discussion ,communication and display as its strategy ,combining with teachers' guidance and comments ,in order to stimulate students' learning interest and promote the overall, initiative and efficient development of the students.
\end{abstract}

\section{Introduction}

Besides imparting knowledge, the other important task of the purpose of education and teaching is to guide students to analyze and solve problems on the basis of the application of their knowledge. With "College English Public Basic" as a compulsory course for students majoring in College English, teachers and students need to cooperate with each other to cultivate students' ability. Therefore, the reform of teaching methods is imperative under the circumstance.In PBL, real problems are used as the students' learning background and autonomous learning and cooperative learning are given a priority. As Cognitive Coaches instead of lecture-givers, teachers provide students with proper guidance, which fully reflects the combination of teachers' guidance and students' functioning as the main body .With the teaching model stimulating students' learning enthusiasm, initiative and creativity greatly, students can not only learn to use their knowledge to solve problems and complete the predetermined teaching goal and curriculum standard with high quality, but can form correct emotional and attitude values as well as a scientific world outlook .Now please analyze the schematic diagram of the model characteristics in table 1.

\section{Application of PBL teaching model}

The implementation of PBL teaching model in the teaching of College English network training: The PBL operation process is summarized as the following basic link respectively: problem presentation ,division of groups,group autonomous learning,group discussion and collaborative learning, group communication ,summary and evaluation .Because the learning in PBL is based on complex problems, these problems should be close to the reality and the real world.

\section{(1) The creation of situations and the introduction of problems}

In the context of the real problem, PBL model emphasizes that under the guidance of teachers, learners should use relevant experience in their original cognitive structure to analyze the necessary knowledge and skills in problem-solving. Also ,they need to use necessary learning materials to assimilate new knowledge actively and establish the connection between the old and new knowledge to complete the construction of significance ,so as to solve problems effectively. In the process of teaching, teachers need to create a proper problem situation and present the problem with a small amount of information to give students a clear understanding. Simultaneously, the problem should be linked to real life so as to further attracts students' attention, stimulate their interest in learning and mobilize their enthusiasm. The teacher has multiple identities including the planner of problem situation, the students' guide and foster , the reviewer of evaluation process and the record of monitoring the whole class in PBL ,instead of the transmitter of knowledge. 


\section{(2)Group learning based on cooperation and exchange}

The second step in PBL is to divide learners into several learning groups due to the necessity of cooperation between learners which is influenced by complexity and authenticity of the problem. The differences of cognitive and personality characteristics of students in the same group contribute greatly to students' problem analyzing and solving from different perspectives .First of all, teachers should make clear of responsibilities and tasks of each groups during the process of problem solving. Meanwhile ,tasks and responsibilities of each group member need to be defined clearly in order to guarantee that all students have the opportunity to study independently and involve into the process of problem-solving actively. According to the complexity of the problem, each group can share information with other groups after their fulfillment of a task independently or in collaboration of others. Next ,teachers need to offer help, guidance and encouragement to students timely in the process. Finally, teachers need to put forward problems and suggestions for improvement on the basis of the review and the summary of knowledge essentials to make sure that students are capable of understanding each problem and acquiring knowledge in system.

\section{(3) Summary and evaluation}

Firstly, in the process of learning ,students need to make an evaluation of their jobs and learning process within the group under the guidance of teachers in order to improve themselves. Then, all the groups can evaluate each other and share their learning experiences and outcomes. At last, teachers need to summarize and improve the deficiency and learning contents , forming a multi-level and diversified evaluation system.

There are two purposes of teaching evaluation :the first is to stimulate students to explore knowledge and the second is to improve teachers' teaching ability. With the diversification of PBL teaching assessment, the teaching evaluation method has characteristics of combining formative assessment with summative assessment, students' self-evaluation with mutual evaluation as well as written language with oral evaluation etc.

Double the overall $\mathrm{Z}$ test applies to the significant test in which two sample sizes(N) are over 30 . Through the test of statistic formula, calculate the $\mathrm{Z}$ value. The formula is as follows:

$$
Z=\frac{X_{1}-X_{2}}{\sqrt{\frac{S_{1}^{2}}{N_{1}}+\frac{S_{1}^{2}}{N_{2}}}}
$$

Before the experiment between the experimental group and control group, the significance probability $\mathrm{P}$ is more than 0.05 , which means that scores of the final exam are roughly the same and that there is no significant difference in the average scores. Results obtained by data $\mathrm{P}$ of the last line in table 2: the significant probability P"0.05 in December,2012, shows that the experimental group and the control group had significant differences in training achievement after the implementation of PBL teaching method for a half year, which is roughly the same as the result respectively in April and June,2013. The experimental results confirm the previously proposed hypothesis that the implementation of PBL teaching model is helpful to improve the training results.

\section{Advantages of application of PBL teaching model in the network technology course}

\section{(1) PBL model leads to the realization of network technology teaching goals}

The general goal of information technology course is to cultivate students' information literacy: Students can collect, process and express information according to the task requirement so as to improve their ability of analyzing and solving problems.The teaching process of PBL :Putting students into a situation of a real problem, students can solve the problem ultimately in the form of group cooperation after the process of collecting relevant information and enough discussion .

Therefore the total goal of information technology course and general purpose of PBL is consistent. With the combination of the two goals, we can not only solve the problem of information technology, but also acquire the knowledge and use related software ,achieving the result that we can shoot two hawks with one arrow. 
(2) PBL teaching method can improve students' learning interest

The application of PBL model in the experimental group can improve learning interest effectively. Students' study in the form of group communication and reporting takes them out of traditional classroom learning, providing those active students with opportunities of projecting themselves. With the class becoming students' battle position and their learning style, students can express themselves freely ,which bring much fun to themselves .Accordingly, their interest in learning will be enhanced significantly.

(3)PBL teaching model contributes to cultivate students' ability to solve practical problems

The network technology course is practical- operation-oriented, with the teaching model combining speaking with practicing. Teachers' excessive teaching, with all the operations carried out in the teachers' unified command, leads to students' lack of creativity and imagination as well as the initiative to explore deeply . The PBL model centered on problems, students learning with problems can mobilize their learning initiative and enthusiasm greatly. The priority of practical problems in learning contributes to cultivate students' ability to solve practical problems with information technology.

(4)PBL teaching model is helpful for the cultivation of students' autonomous learning

With PBL problem-centered, students have to find relevant information with all resources available to solve problems. In the whole process, they need to make their learning plans and construct new knowledge on the basis of the old . So they will soon become independent learners and thinkers in this teaching mode.

\section{Conclusion}

In the implementation of PBL, the cooperation and discussion between teams ARE indispensable, because group discussion is the main model of learning. As students make a discussion in group to find the best solution to solve the problem together, the team cooperation is not only the process of students' mutual help and the exchange of knowledge, but also the process of mutual assistance and mutual communication of feelings .With the problems in PBL teaching model real and complex, it is difficult for a individual to complete. Thus students need to work in group, analyzing problems and collecting related information together, so as to solve the problem. Through the group cooperative learning, they will finally become such persons who are both willing to collaborate with others and good at teaming up with others.

\section{Reference}

[1]Chrysanthe Demetry and John A. Orr. 2009. Quality Assurance in Engineering Education in the United States Lance Schachterle, Engineering Education Quality Assurance, Part 3, pp:163-180.

[2]A.V.Valiulis and D.Valiulis. 2009. Engineering Education Quality Assurance: The Essential Pillar of Higher Education Reform in Lithuania. Engineering Education Quality Assurance, Part3, pp:191-198.

[3]Andreas Hoecht. 2006. Quality Assurance in UK Higher Education: Issues of Trust, Control, Professional Autonomy and Accountability .Higher Education, vol.51, pp:541-563.

[4]A. Chuchalin, O. Boev and A. Kriushova.2009. Quality Assurance in Engineering Education and Modernization of Higher Education in Russia. Engineering Education Quality Assurance, Part 3, pp:87-95.

[5]Hao V. Le and Kim D. Nguyen. 2009. Quality Assurance in Vietnam’s Engineering Education. Engineering Education Quality Assurance, Part 3, pp:97-106. 